\title{
The role of fasting versus non-fasting triglycerides in ischemic stroke: a systematic review
}

\section{Christopher Leonards ${ }^{1+}$, Martin Ebinger ${ }^{1+*}$, Jana Batluk ${ }^{1}$, Uwe Malzahn ${ }^{1}$, Peter Heuschmann ${ }^{1}$ and Matthias Endres ${ }^{1,2}$}

1 Center for Stroke Research Berlin, Charité - Universitätsmedizin, Berlin, Germany

2 Klinik und Poliklinik für Neurologie, Charité - Universitätsmedizin, Berlin, Germany

Edited by:

Louis R. Caplan, Harvard Medical School, USA

Reviewed by:

Natan M. Bornstein, Tel Aviv University, Israel

Michael Brainin, Donau-Universität Krems, Austria

\section{*Correspondence:}

Martin Ebinger Center for Stroke

Research Berlin, Charité -

Universitätsmedizin Berlin, Campus

Mitte, Charité Platz 1, D-10117 Berlin,

Germany.

e-mail:martin.ebinger@charite.de

${ }^{+}$Christopher Leonards and Martin

Ebinger have equally contributed to the review.
Objective:To synthesize results from pertinent studies and determine if fasting and/or non-fasting triglycerides are a risk factor for ischemic stroke. Method: We performed two independent systematic literature searches using the PubMed and ScienceDirect databases to identify studies examining the relationship between fasting and non-fasting triglyceride concentrations and ischemic stroke risk. A meta-analysis was performed using ischemic stroke as a primary endpoint. Results: Twenty-five reports were identified, including 13 prospective cohort and 12 casecontrol studies. Baseline characteristics, study samples, methods, and primary outcomes varied. Of 13 prospective cohort studies, nine assessed triglyceride concentrations in the fasting state. Seven of these identified triglycerides as an independent risk factor for ischemic stroke risk ( $n=1624$ ischemic cases). Three prospective cohort studies identified a positive association between elevated non-fasting triglyceride concentrations and ischemic stroke risk ( $n=2050$ ischemic cases). One prospective cohort study that compared fasting and non-fasting triglycerides identified only non-fasting triglycerides as an independent risk factor for ischemic stroke. Of 12 case-control studies identified, five identified a positive relationship between ischemic stroke risk and elevated fasting triglycerides ( $n=838$ cases). Seven case-control studies were included in the meta-analysis ( $n=1996$ ischemic stroke cases), revealing an odds ratio of $1.15(95 \% \mathrm{Cl}, 1.08-1.21)$. Conclusions: The available data are inconsistent. The relationship between triglyceride levels and ischemic stroke needs further investigation under standardized conditions. We recommend a standardized triglyceride tolerance test to further investigate the associations between fasting versus non-fasting triglyceride levels and ischemic stroke.

Keywords: ischemic stroke, triglycerides, epidemiology

\section{INTRODUCTION}

Though it is well established that the number and severity of vascular risk factors contribute to stroke risk (Blumenfeld, 2002; Towfighi and Ovbiagele, 2008), it is clear that the list of known risk factors to date is not complete. Triglycerides are circulating lipid components that are among the many long-speculated modifiable risk factors for ischemic stroke (Albrink and Man, 1959; Zimmermann et al., 2004). However, the clinical usefulness of plasma triglyceride concentrations as an independent risk factor of ischemic stroke risk remains controversial (Tell et al., 1988; Ridker, 2008). Some claim that elevated triglyceride levels are strong independent factors increasing risk of ischemic stroke (Lindenstrom et al., 1994; Ahmed et al., 1999; Milionis et al., 2005) while others have found the relationship either to exist only in women (Bansal et al., 2007), men (Salonen et al., 1982), or not at all (Haheim et al., 1993; Bowman et al., 2003).

Some of the discrepancy in the literature could be due to genetic heterogeneity within study samples (Havasi et al., 2006). Indeed, lipid profiles can vary largely at the individual level, and are affected by factors like ethnicity, alcohol consumption, and menopausal status (Austin, 1991; Sarwar et al., 2006; Ridker, 2008). Rhoads and Feinleib (1983), for instance, found that Puerto Rican and Japanese men had higher median triglyceride values than men of Caucasian descent. As larger samples of stroke patients of different ethnicities are being studied however (Sarwar et al., 2006), it is becoming increasingly apparent that methodological differences across studies might be playing a larger role (Bansal et al., 2007).

Traditionally measured in the fasting state to avoid variability (Ridker, 2008), mounting evidence supports the assessment of non-fasting triglyceride concentrations to determine stroke risk (Zilversmit, 1979; Ryu et al., 1992; Bengtsson et al., 1993; Stensvold et al., 1993; Jeppesen et al., 1998; Abdel-Maksoud and Hokanson, 2002). Because no consistent set of prospective cohort data specifically comparing fasting versus non-fasting triglycerides as a measure of stroke risk exist, it remains unclear which state is more efficacious.

It is also possible that risk could vary across genders, as one metaanalysis found that plasma triglyceride levels in women associated twice as strongly with cardiovascular disease risk than those in men (Hokanson and Austin, 1996). 
The purpose of this review is to summarize and synthesize results from pertinent studies in an effort to determine if fasting and/or non-fasting triglycerides are a risk factor for ischemic stroke. We hypothesized that elevated non-fasting plasma triglyceride concentrations are indicative of stroke risk.

\section{MATERIALS AND METHODS}

SEARCHING DATA SOURCES

This review was conducted in accordance with MOOSE guidelines (Stroup et al., 2000). We identified original epidemiological studies assessing the relationship between stroke risk and fasting or non-fasting triglyceride concentrations using two independent computerized literature searches (Figure 1). The PubMed and ScienceDirect databases were searched by Christopher Leonards and Jana Batluk between April 14th and 27th April, 2010, using the medical subject heading (MESH) terms "triglycerides" and "stroke." Hand searching was also performed of all included studies and relevant review articles. Unpublished studies were identified by searching the book of abstracts from the European Stroke Conferences ranging from the years 2006 through 2008.

\section{STUDY ELIGIBILITY}

The review included any human prospective cohort, case-control, and nested case-control study having to do either directly or indirectly with ischemic stroke published or translated into the English language. Because this review focuses exclusively on ischemic stroke risk, studies were only eligible for inclusion if a computed tomography scan or magnetic resonance imaging had been performed on patients to distinguish between ischemic and hemorrhagic strokes.

\section{INCLUSION CRITERIA}

Case-control and prospective cohort studies were included if they had at least 100 participants per group and a statistical analysis had been conducted measuring the relationship between triglyceride levels and stroke endpoint (fatal and/or non-fatal ischemic stroke and transient ischemic attack). Additionally, we excluded all studies that did not include a specific ischemic stroke patient subset within their study, thereby excluding studies that focused exclusively on other forms of stroke (e.g., subarachnoid hemorrhage). This was performed in an effort to minimize

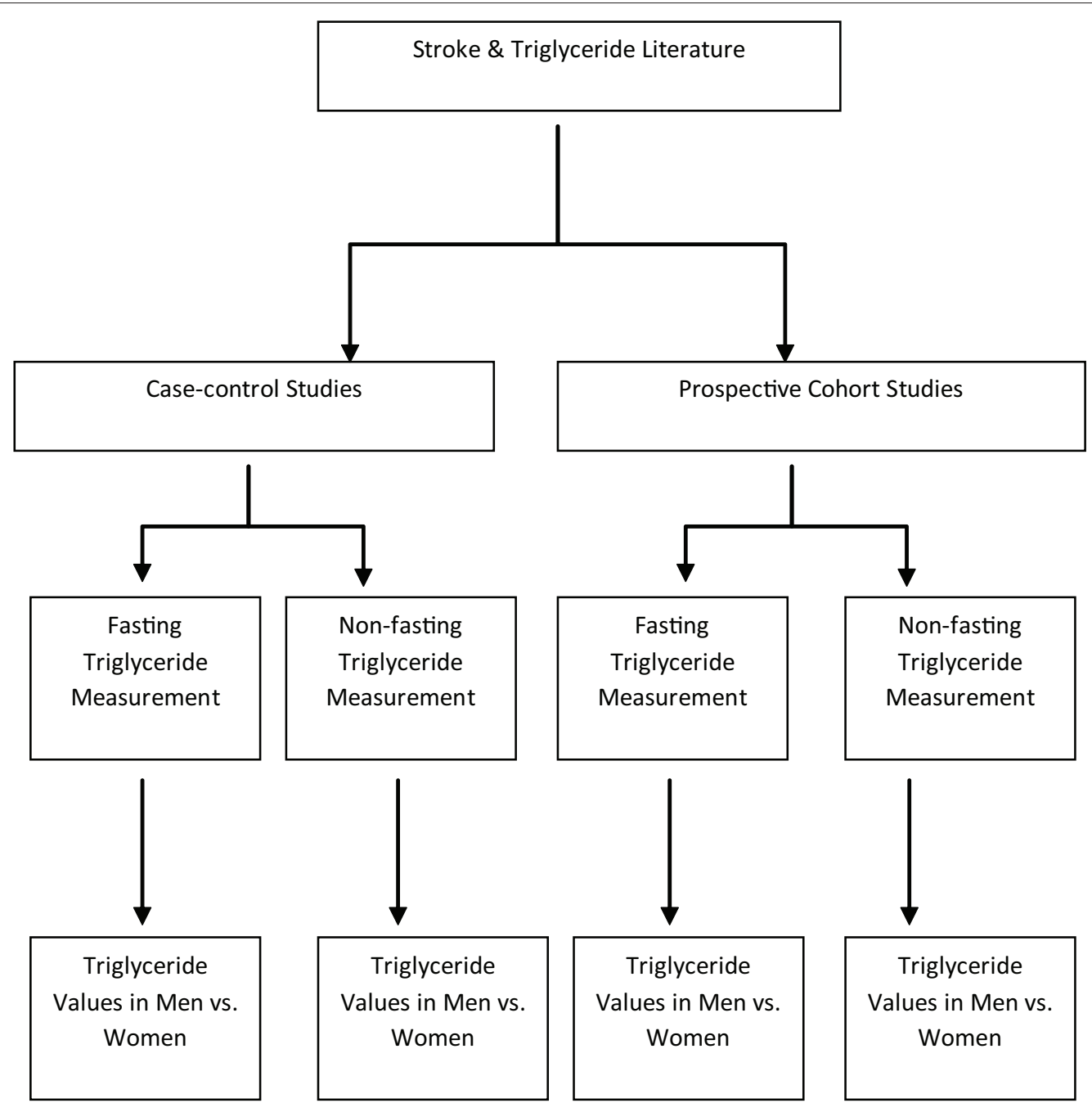

FIGURE 1 | Flow diagram illustrating the subdivisions of the stroke literature pertaining to triglyceride levels. 
potential confounds, as triglyceride levels have been more strongly connected with ischemic than hemorrhagic stroke risk (Austin et al., 2000; Sarti and Gallagher, 2006). When more than one publication using the same sample was found, the publication with the most recent, complete data set was included. Results from meta-analyses are discussed herein, but were excluded from our analyses.

\section{DATA EXTRACTION}

The data extracted from eligible reports are exhibited in Figure 2. Data were extracted by one author (Christopher Leonards) and reviewed independently (Martin Ebinger) to assure accuracy. Authors were not contacted for additional or unpublished data. Studies were then categorized based on study design and the direction of association found (Tables 1 and 2).

\section{META-ANALYSIS}

We performed a meta-analysis of case-control studies that assessed plasma triglycerides and the risk of ischemic stroke using the MIX software package (Bax et al., 2006). Heterogeneity was assessed using the $Q$ and $I^{2}$ statistics and we calculated a pooled odds ratio within a fixed effect meta-analysis. Because stroke endpoint, fasting status, and statistical methods varied across studies, not all casecontrol studies were included.

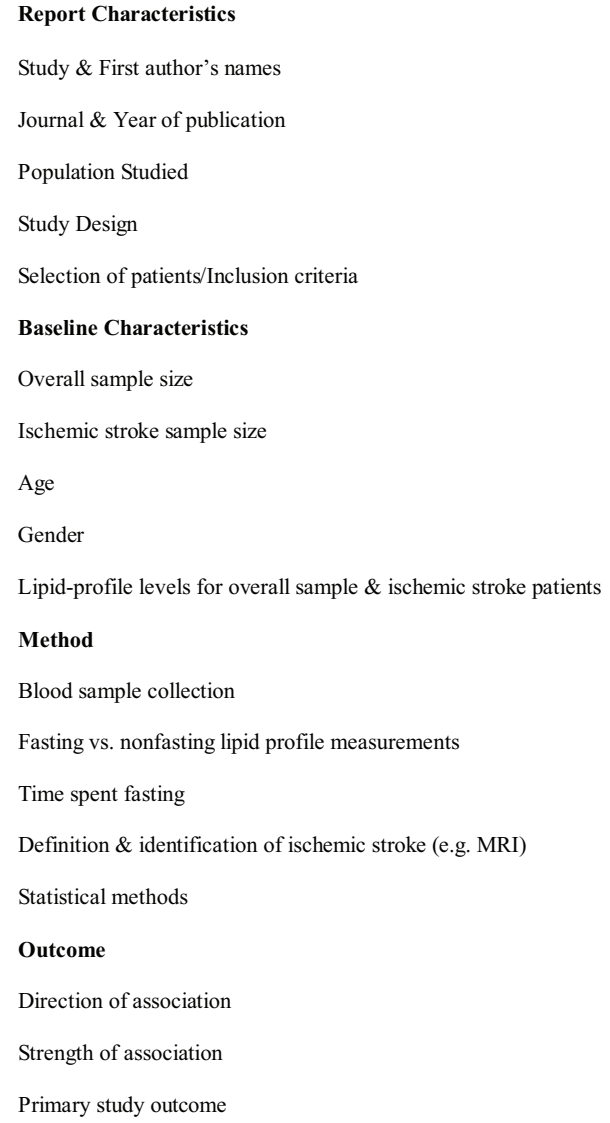

FIGURE 2 | Panel illustrating data extracted from eligible reports.
For some case-control studies no logistic regression was performed and no odds ratios are reported. If only mean triglyceride values and SD's were given for cases and controls, we decided not to convert the corresponding standardized differences to odds ratios and thereafter include these studies in our meta-analysis. First, this would not yield adjusted odds ratios and, second, the corresponding model assumptions which justify such procedures (e.g., Hasselblad and Hedges, 1995; Whitehead, 2002) are very specialized and in practice difficult to test. Thus, we only included case-control studies that reported odds ratios.

\section{RESULTS}

Of 6896 citations identified by the computerized literature search in ScienceDirect and 1065 in PubMed, 35 epidemiological human studies examining the relationship between triglyceride concentrations and stroke risk that were identified by review of the title, abstract, and hand searching of references (Figure 3). Of these 35 identified, 25 reports matched the inclusion criteria and are presented according to study design in Table 1 (prospective cohort) and Table 2 (case-control). The grounds for paper dismissal were lack of a specific ischemic stroke group $(n=6)$ (Rhoads and Feinleib, 1983; Haheim et al., 1993; Njolstad et al., 1996; Wannamethee et al., 2000; Shearman et al., 2005; Tokuda and Stein, 2005), duplicated data sets $(n=2)$ (Lindenstrom et al., 1994; Nordestgaard et al., 2007), and two full text papers could not be accessed (Lapidus et al., 1985).

\section{PROSPECTIVE COHORT STUDIES}

Thirteen prospective cohort studies (Table 1) were identified with a total of 99479 participants, and 4675 ischemic strokes that occurred during a mean follow-up period of 9.6 years. Samples varied regarding demographics and baseline characteristics. Nine of the prospective cohort studies measured triglyceride concentrations in the fasting state (Salonen et al., 1982; Aronow et al., 1988; Simons et al., 1998; Psaty et al., 2001; Tanne et al., 2001; Shahar et al., 2003; Onat et al., 2006; Nakamura et al., 2009), three non-fasting (Gordon et al., 1981; Iso et al., 2007; Freiberg et al., 2008), and one examined fasting versus non-fasting concentrations (Bansal et al., 2007). Fasting times across studies were variable, and ranged from 4 to $12 \mathrm{~h}$.

\section{NON-FASTING PROSPECTIVE COHORT STUDIES}

Of the four studies that examined non-fasting triglyceride concentrations, three found that elevated triglyceride concentrations were independent risk factors for ischemic stroke in a sample including 1785 ischemic events after follow-up (Iso et al., 2007; Freiberg et al., 2008). One study found that triglyceride concentrations were not related to ischemic stroke risk in a sample of 150 ischemic stroke patients (Gordon et al., 1981). Of the three positive studies, one was conducted in women only and examined the risk of ischemic stroke across a fasting (minimum 8-h fast) and non-fasting group and found that in a sample including 265 ischemic events only non-fasting triglyceride concentrations were indicative of ischemic stroke risk (HR per 1-SD increase in triglyceride levels 1.98, 95\% CI 1.21-3.25) (Bansal et al., 2007). 


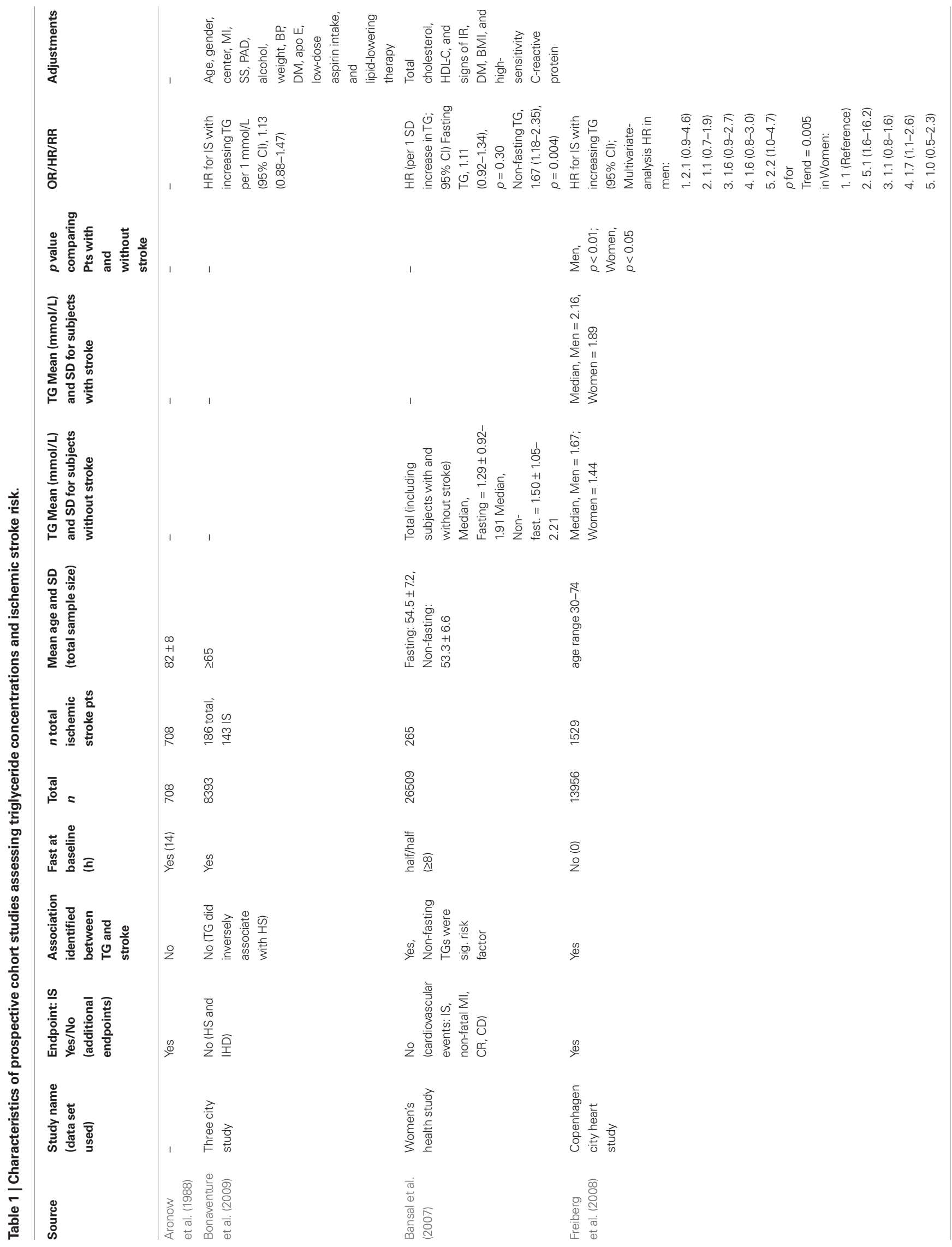




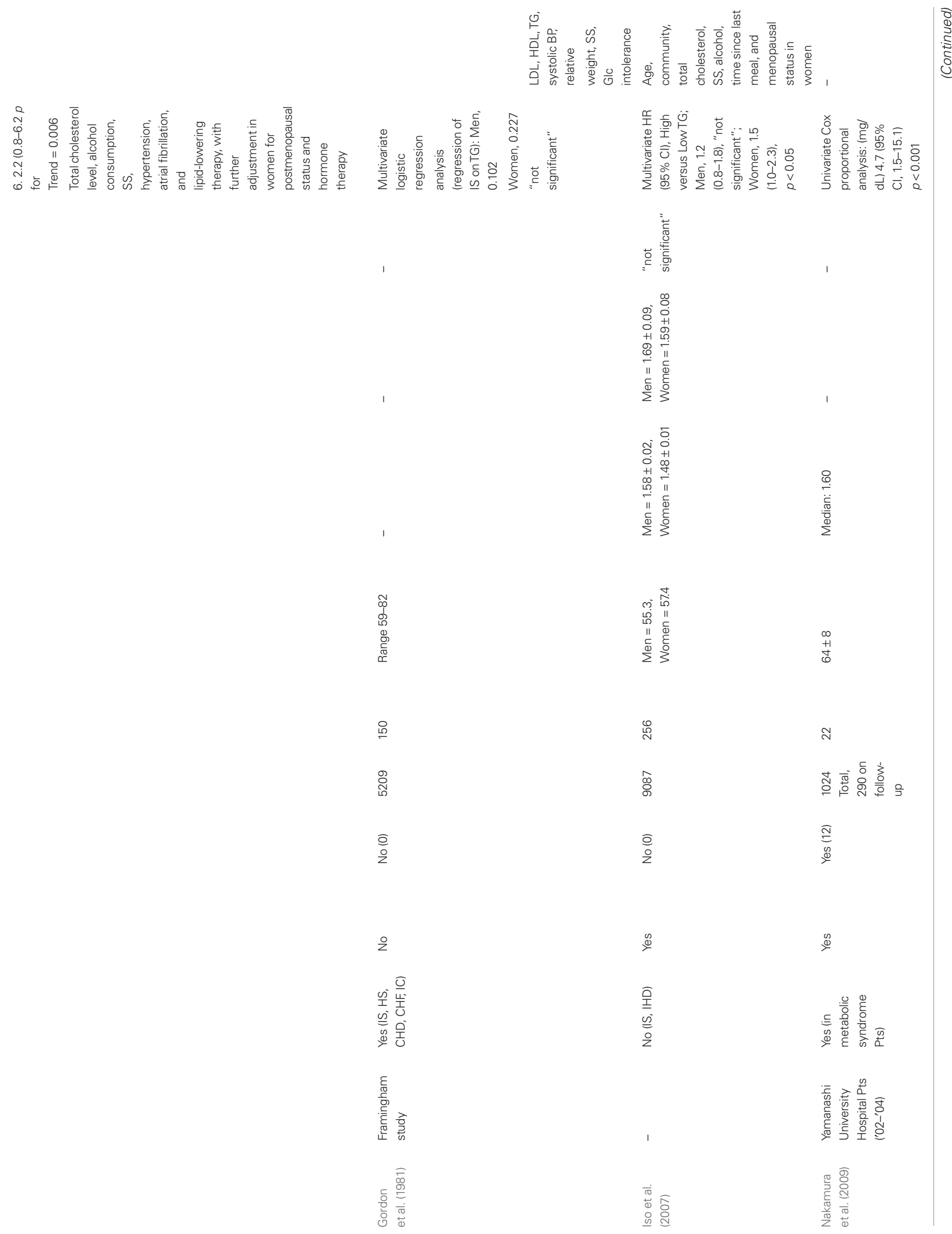




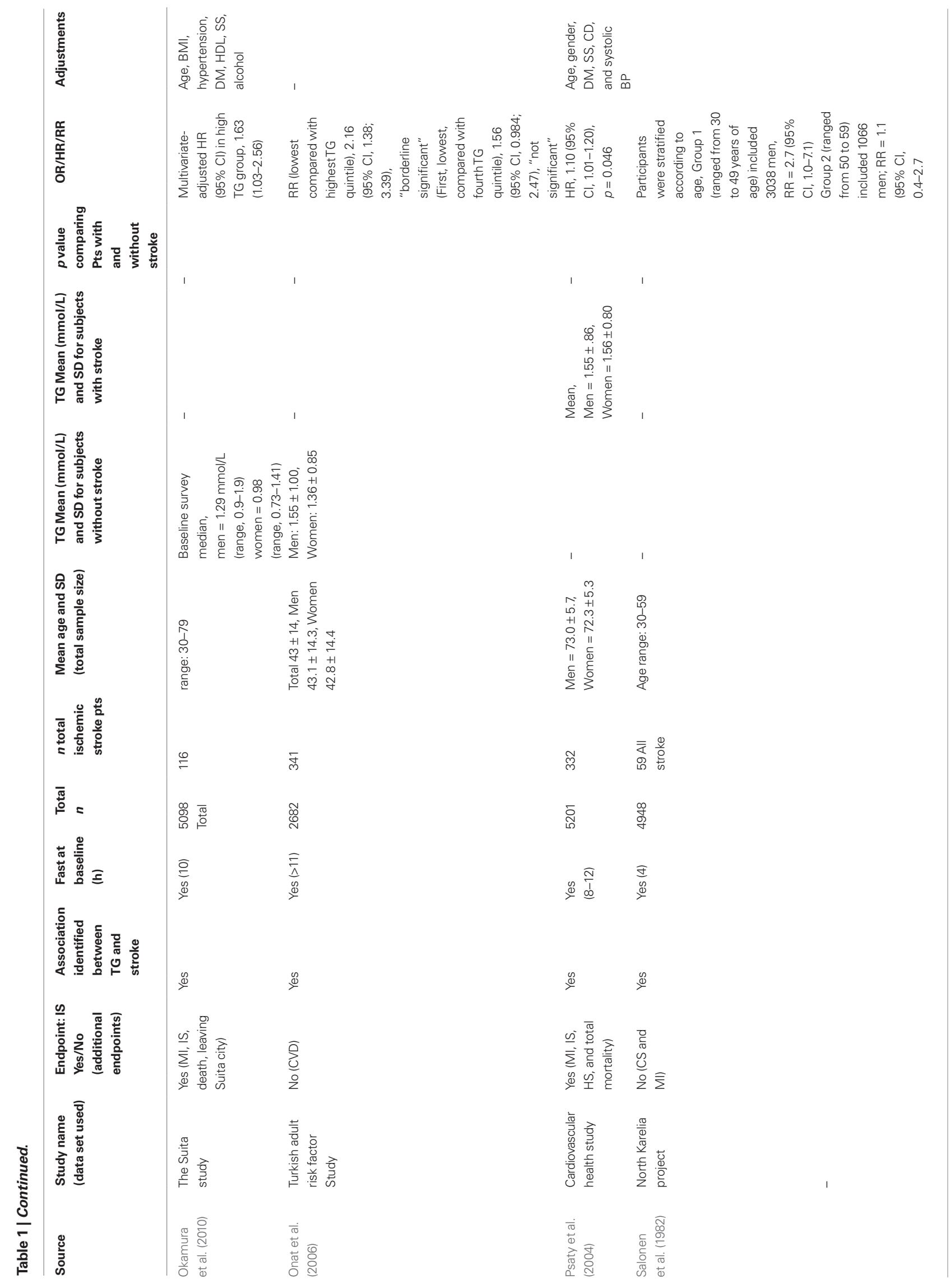




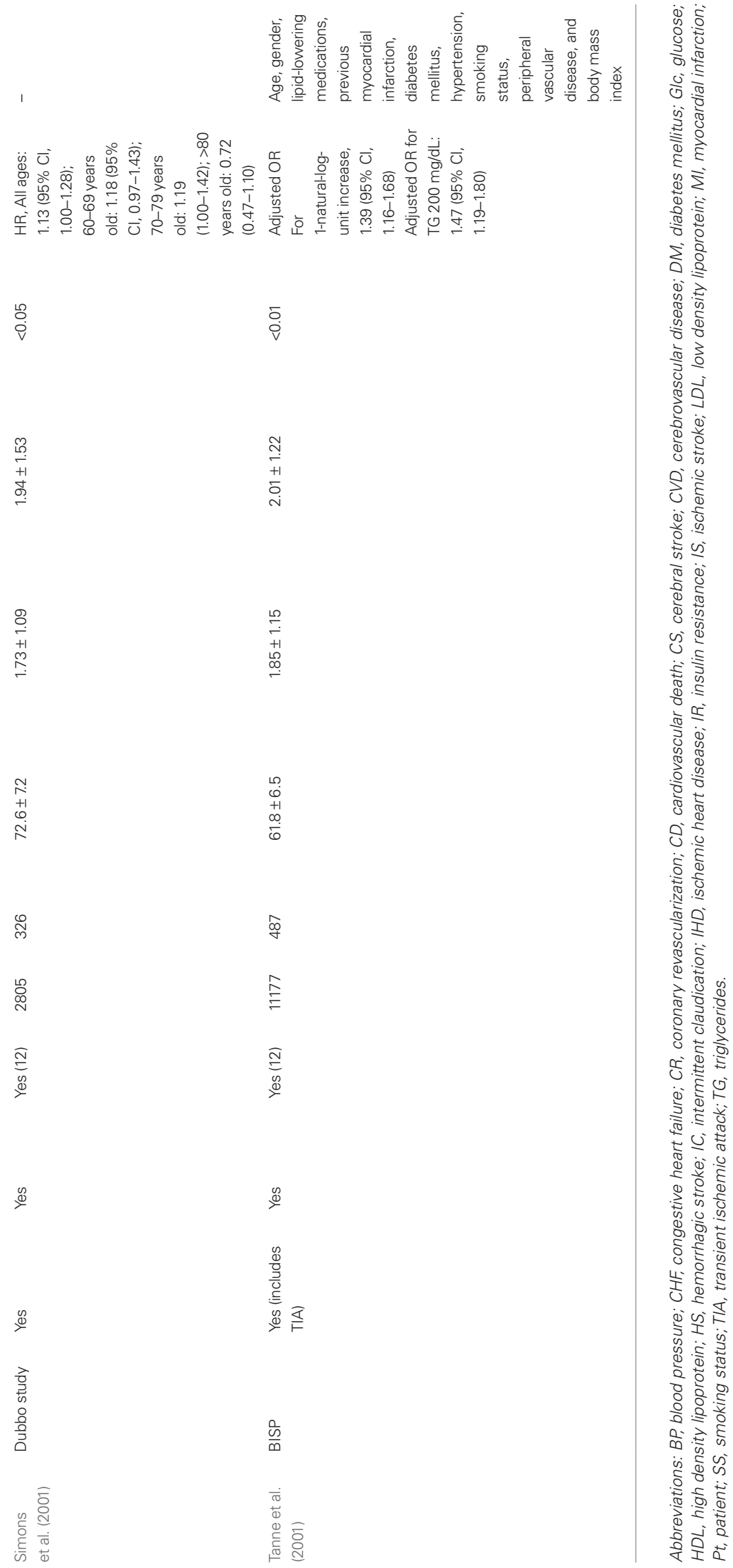




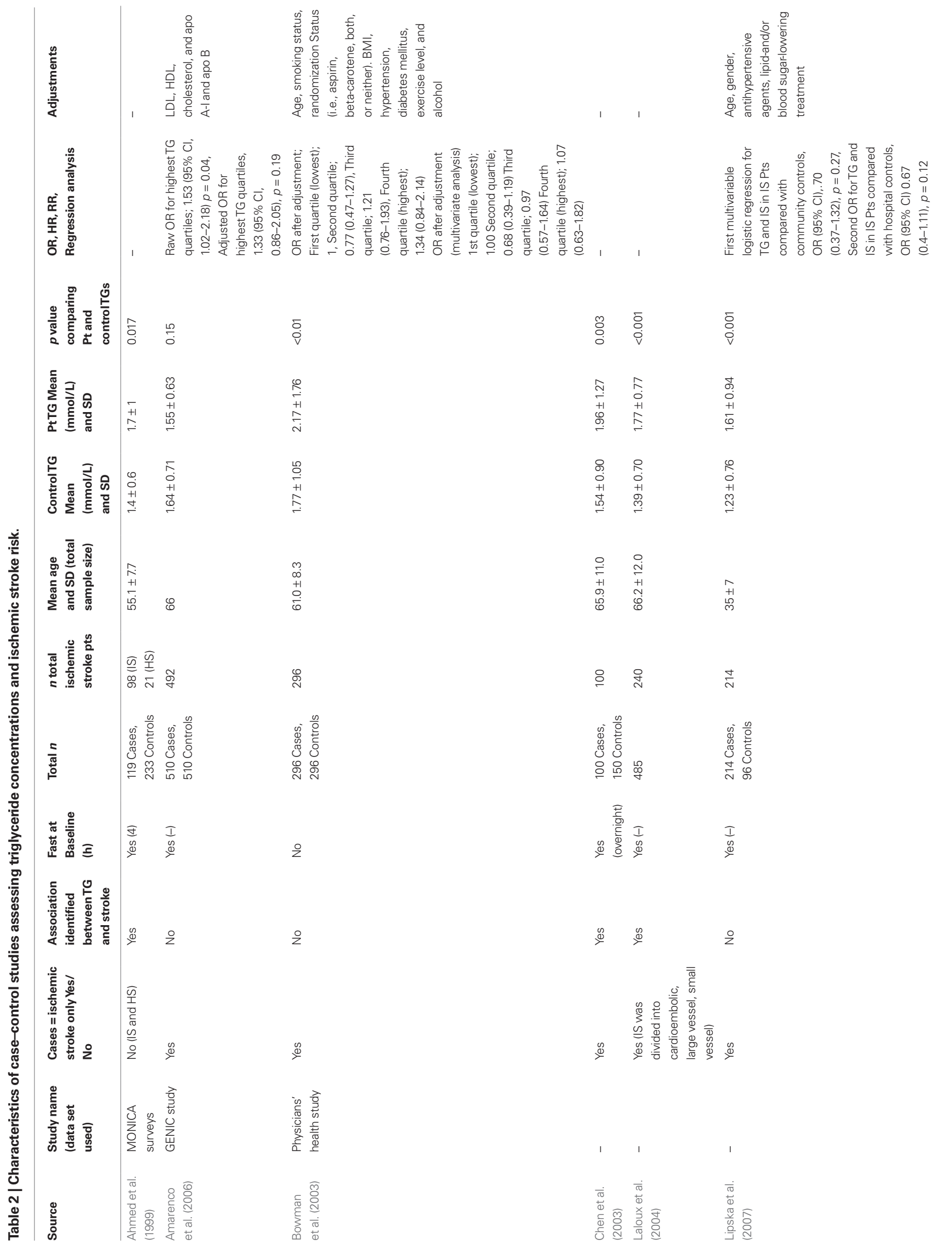


Leonards et al.

Triglycerides and ischemic stroke

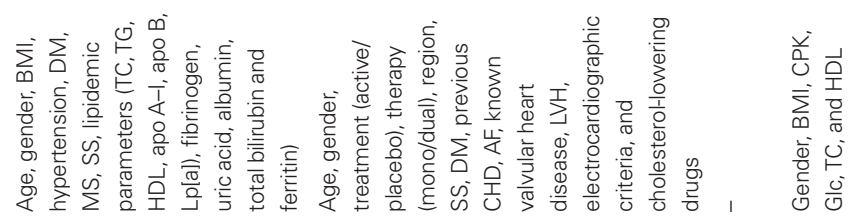

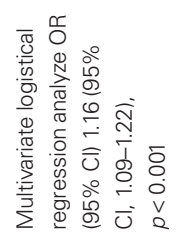

$\bar{\delta}$
$\dot{0}$
$\mathrm{v}$

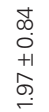

8
0
0
+1
+
+

$\stackrel{\infty}{\curvearrowright}$

๕ִ

$\begin{array}{ll} & 0 \\ w & 0 \\ 0 & 0 \\ 0 & 0 \\ 0 & 0 \\ 0 & 0 \\ 8 & 0 \\ 0 & 0\end{array}$



$\stackrel{\infty}{2}$

$\stackrel{\infty}{2}$

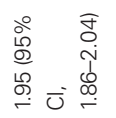

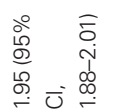

10
8
6

$\stackrel{\mathfrak{F}}{\forall}$

$\begin{array}{ll} & 0 \\ 0 & 0 \\ 0 & 0 \\ 0 & 0 \\ 0 & 0 \\ 0 & 0 \\ 0 & 5 \\ 0 & 0\end{array}$

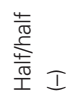

운

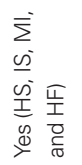

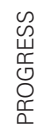

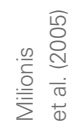

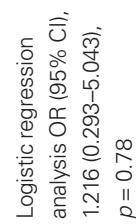

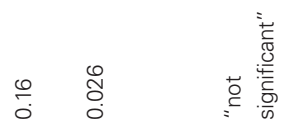

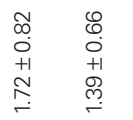

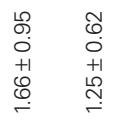

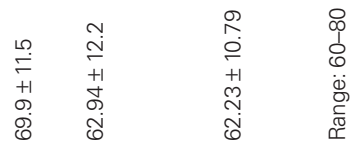

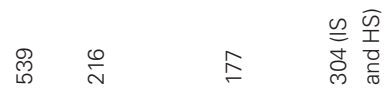

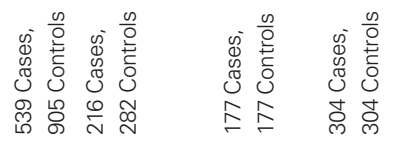

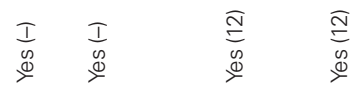

욜 운
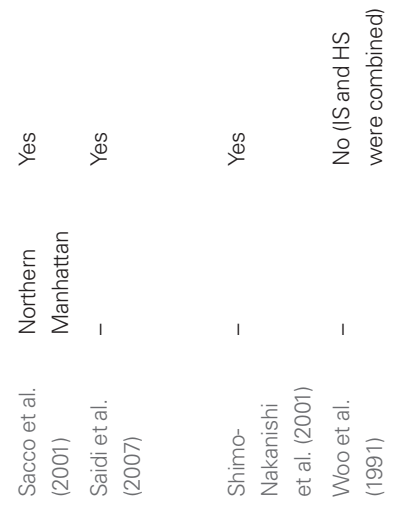

www.frontiersin.org

October 2010 | Volume 1 | Article 133 | 9 


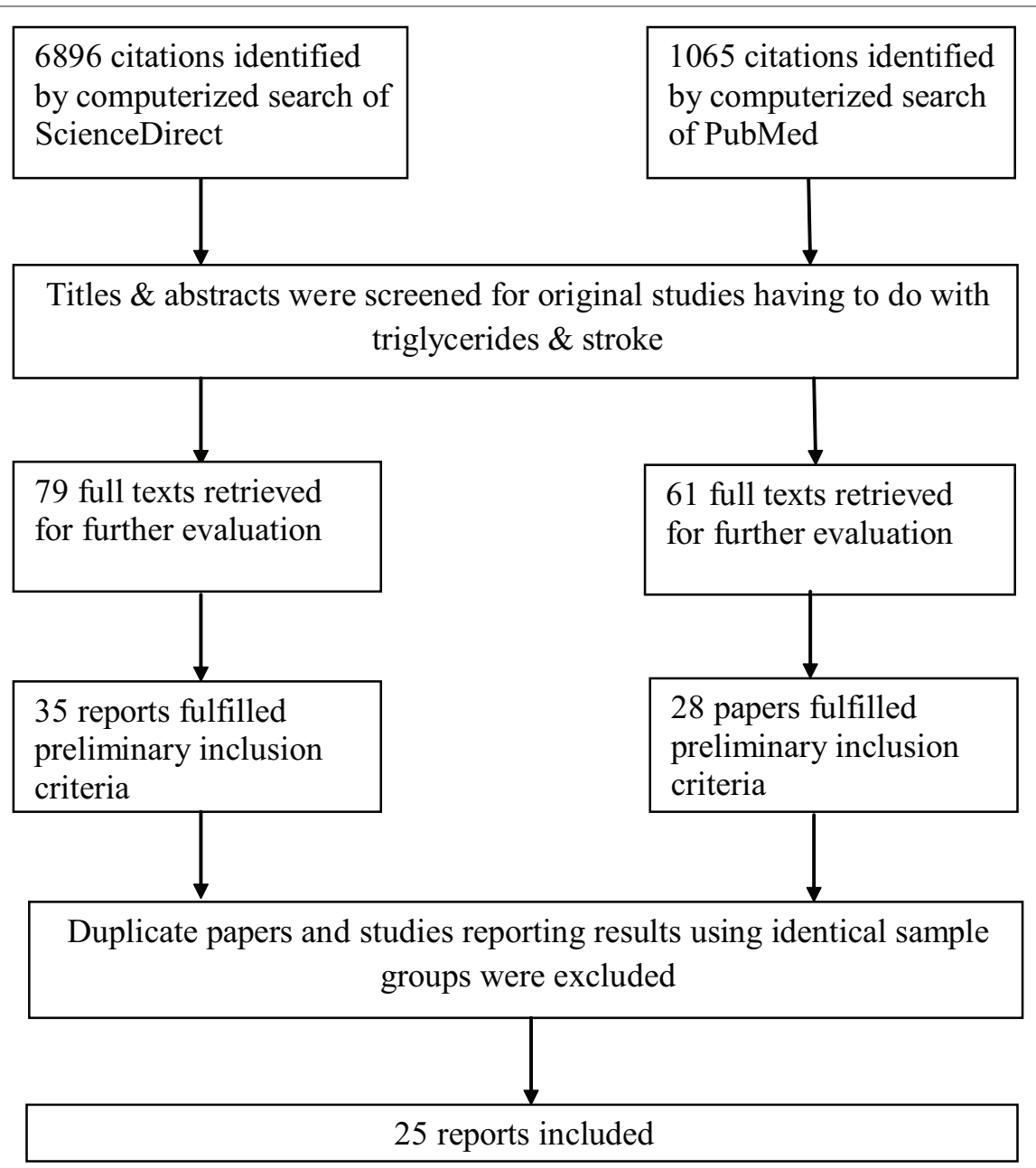

FIGURE 3 | Flow diagram outlining the study inclusion process. MESH terms: "triglycerides" plus "stroke".

\section{FASTING PROSPECTIVE COHORT STUDIES}

Seven of the nine prospective cohort studies that measured triglycerides in the fasting state identified elevated plasma triglyceride concentrations as an independent risk factor for ischemic stroke with 1624 combined ischemic events (Salonen et al., 1982; Simons et al., 1998; Psaty et al., 2001; Tanne et al., 2001; Onat et al., 2006; Nakamura et al., 2009). Two studies, with 1013 combined ischemic events, found no association to exist between ischemic stroke risk and elevated triglyceride levels (Aronow et al., 1988; Shahar et al., 2003).

\section{CASE-CONTROL STUDIES}

Twelve case-control studies were identified (Table 2) including 3841 cases and 4715 controls. Three studies were nested within randomized clinical trials (Ahmed et al., 1999; Bowman et al., 2003; Patel et al., 2005), and baseline characteristics varied as did sample populations. One study (Bowman et al., 2003) measured triglycerides in the non-fasting status.

Another study (Patel et al., 2005) measured both fasting and non-fasting plasma triglyceride concentrations. All other studies measured triglycerides in the fasting state only. Length of fasting varied between 4 and $12 \mathrm{~h}$ and was often not reported $(n=5)$.

\section{NON-FASTING CASE-CONTROL STUDIES}

Two studies reported on triglyceride levels in the non-fasting state (Bowman et al., 2003; Patel et al., 2005). Both found no relationship between ischemic stroke risk and elevated plasma triglyceride concentrations (1191 cases). Interestingly however, though one study (Patel et al., 2005) reported no significant relationship to exist, Bowman et al. (2003) reported a significant difference between mean baseline non-fasting triglyceride concentrations in cases and controls, reporting a mean control group triglyceride concentration of $1.77 \pm 1.05 \mathrm{mmol} / \mathrm{L}$ and mean case concentration of $2.17 \pm 1.76 \mathrm{mmol} / \mathrm{L}(p<0.01)$.

\section{FASTING CASE-CONTROL STUDIES}

Ten of the 12 case-control studies measured triglycerides in the fasting state (Table 2), two of which, assessed triglyceride concentrations in the acute stroke state $(\leq 48$-h post ictus) (Woo et al., 1991; Shimo-Nakanishi et al., 2001). Of these 10 fasting state studies, five (838 ischemic cases) reported a positive association between increased plasma triglyceride levels and ischemic stroke risk (Ahmed et al., 1999; Chen et al., 2003; Laloux et al., 2004; Milionis et al., 2005; Saidi et al., 2007), and four (883 ischemic 
cases) found no relationship to exist (Woo et al., 1991; Sacco et al., 2001; Shimo-Nakanishi et al., 2001; Patel et al., 2005). One study combining ischemic and hemorrhagic cases found no relationship between fasting triglyceride levels and stroke (Woo et al., 1991).

\section{GENDER DIFFERENCES}

A number of studies have directly investigated the relationship between triglycerides and stroke in both men and women with varying results. In a study conducted by Njolstad et al. (1996), elevated fasting plasma triglycerides were significant risk factors for ischemic stroke in women. A women's study conducted by Bansal et al. (2007) showed similar findings measuring non-fasting triglycerides. Of five men's studies, three found no relationship between ischemic stroke and non-fasting triglycerides to exist (Rhoads and Feinleib, 1983; Haheim et al., 1993; Wannamethee et al., 2000) and two identified a positive relationship (Salonen et al., 1982; Iso et al., 2007). Taking both genders into account, several studies have found both fasting and non-fasting triglycerides to be an independent risk factor for ischemic stroke (Ahmed et al., 1999; Iso et al., 2007; Freiberg et al., 2008).

\section{META-ANALYSIS}

Seven case-control studies (Woo et al., 1991; Bowman et al., 2003; Milionis et al., 2005; Patel et al., 2005; Amarenco et al., 2006; Lipska et al., 2007; Saidi et al., 2007) were included in the meta-analysis, with a total of 5263 participants (for odds ratios, see Figure 4).

Based on the Q-statistic, the null-hypothesis that all seven studies share a common odds ratio could not be rejected $(Q=6.57$, $p=0.36$ ). There was no significant excess variation. The very low value for $I^{2}\left(I^{2}=8.76 \%\right)$ indicated that only a very small proportion of the observed variance reflected real differences between the seven

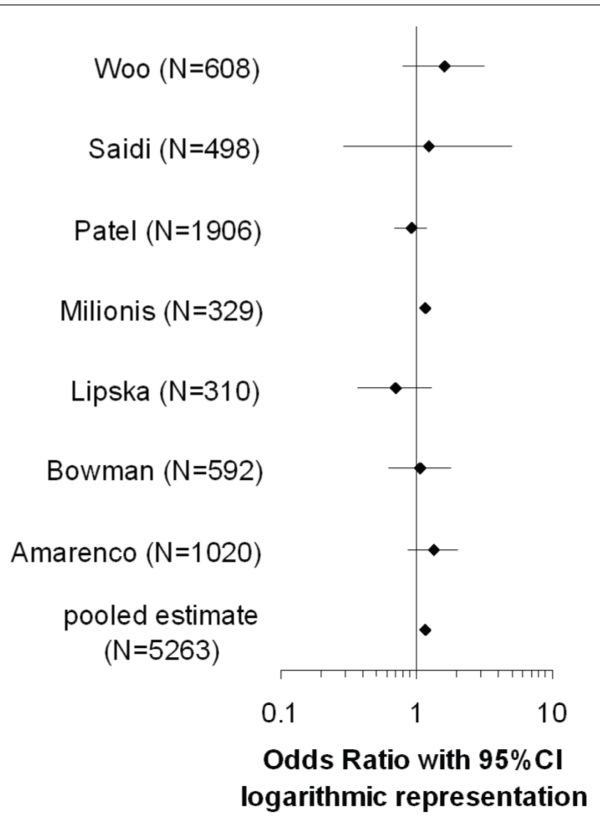

FIGURE 4 | Forrest plot illustrating the odds ratios $(95 \% \mathrm{Cl})$ of studies included in the meta-analysis. odds ratios. There was, however, an uncertainty in $I^{2}$ corresponding to a broad $95 \%$ CI. The pooled odds ratio within a fixed effect model (1.15, 95\% CI, 1.08-1.21) and the estimated mean odds ratio within a random effects model $(1.13,95 \% \mathrm{CI}, 1.02-1.25)$ were very close. Removing the only study (Bowman et al., 2003) with nonfasting TG values in a sensitivity analysis did not change the result. However, when another study was excluded (Milionis et al., 2005) sensitivity analysis revealed loss of significance (for study inclusion criteria, see section Materials and methods).

\section{DISCUSSION}

This review revealed that a vast array of conflicting results exist in the literature with regard to the impact that triglycerides have on ischemic stroke risk (Tables 1 and 2). Out of 12 case-control studies only seven studies that reported odds ratios were included in our meta-analysis. It revealed a significant odds ratio of 1.15 (95\% CI, 1.08-1.21) but the significance was attributable to a single study (Milionis et al., 2005) only. A sensitivity analysis revealed that this study contributed with a high weight to our meta-analysis and therefore strongly influenced our findings. In fact, significance was lost after the removal of this study [pooled odds ratio with $95 \%$ CI within a fixed effect model: 1.03 ( 0.85 , 1.25), estimate for the mean odds ratio with $95 \% \mathrm{CI}$ for a random effects model: $1.03(0.85,1.26)]$. Our literature search showed that very few $(n=3)$ original studies have specifically compared fasting with non-fasting triglyceride levels in relation to ischemic stroke risk (Patel et al., 2005; Bansal et al., 2007; Nordestgaard et al., 2007). Moreover, we observed that neither the time elapsed since the most recent meal, nor the content of that meal have been standardized.

Thus, to quell the debate between fasting versus non-fasting triglycerides, it might be beneficial to develop a standardized paradigm for measuring triglycerides. An oral triglyceride tolerance test (oTTT) has recently been suggested as a possible approach (Mohanlal and Holman, 2004; Bansal et al., 2007; Ridker, 2008; Ebinger et al., 2010).

Our review and meta-analysis have a few limitations. First, only those studies published in the English language were included. Secondly, though we specified our inclusion and exclusion criteria no further method quality appraisal was performed. Third, various final endpoints were included in this review (ischemic stroke was the only endpoint used in our meta-analysis). Fourth, we did not differentiate between studies on first versus recurrent stroke.

One advantage of our meta-analysis is that we examined only ischemic stroke. As stroke is a heterogeneous condition, it is possible that plasma triglyceride concentrations correlate differently to various subtypes. Studies performed by Bonaventure et al. (2009) and Psaty et al. (2004) have found an inverse relationship between triglyceride concentrations and hemorrhagic stroke. This distinction between ischemic and hemorrhagic stroke could be of importance, as studies that combine all forms of stroke may be negating possible significant associations. Future work might include examining triglycerides as a risk factor for all stroke subtypes and across the various subtypes of ischemic stroke. We did not differentiate between the embolic, thrombotic, or lacunar subtypes of ischemic stroke as we found very little published information on the topic (Laloux et al., 2004). 
While other reviews (Nordestgaard et al., 2007; Antonios et al., 2008; Labreuche et al., 2009) suggested that triglycerides may be associated with ischemic stroke, we concluded that the available data are inconsistent. The relationship between triglyceride levels and ischemic stroke needs further investigation under standardized conditions. Though the available data are mainly composed of studies performed using fasting triglyceride values, some elegant non-fasting prospective cohort studies identified a correlation between non-fasting triglycerides and ischemic stroke risk (Bansal et al., 2007; Freiberg et al. 2008). Therefore, further

\section{REFERENCES}

Abdel-Maksoud, M. F., and Hokanson, J. E. (2002). The complex role of triglycerides in cardiovascular disease. Semin. Vasc. Med. 2, 325-333.

Ahmed, E., Trifunovic, J., Stegmayr, B., Hallmans, G., and Lefvert, A. K. (1999). Autoantibodies against oxidatively modified LDL do not constitute a risk factor for stroke a nested case-control study. Am. Heart Assoc. 30, 2541-2546.

Albrink, M., and Man, E. (1959). Serum triglycerides in coronary artery disease. Arch. Intern. Med. 103, 4-8.

Amarenco, P., Labreuche, J., Elbaz, A., Touboul, P. J., Driss, F., Jaillard, A., and Bruckert, E. (2006). Blood lipids in brain infarction subtypes. Cerebrovasc. Dis. 22, 101-108.

Antonios, N.,Angiolillo, D. J., and Silliman, S. (2008). Hypertriglyceridemia and ischemic stroke. Eur. Neurol. 60, 269-278.

Aronow, W. S., Gutstein, H., Lee, N. H., and Edwards, M. (1988). Three-year follow-up of risk factors correlated with new atherothrombotic brain infarction in 708 elderly patients. Angiology 39, 563.

Austin, M. A. (1991). Plasma triglyceride and coronary heart disease. Arterioscler. Thromb. Vasc. Biol. 11, 2-14.

Austin, M. A., McKnight, B., Edwards, K. L., Bradley, C. M., McNeely, M. J., Psaty, B. M., Brunzell, J. D., and Motulsky,A. G. (2000). Cardiovascular disease mortality in familial forms of hypertriglyceridemia: a 20-year prospective study. Am. Heart Assoc. 101, 2777-2782.

Bansal, S., Buring, J. E., Rifai, N., Mora, S., Sacks, F. M., and Ridker, P. M. (2007). Fasting compared with nonfasting triglycerides and risk of cardiovascular events in women. JAMA 298, 309-316.

Bax, L., Yu, L. M., Ikeda, N., Tsuruta, H., and Moons, K. G. (2006). Development and validation of MIX: comprehensive free software for meta-analysis of causal research data. BMC Med. Res. Methodol. 6, 50.

Bengtsson, C., Bjorkelund, C., Lapidus, L., and Lissner, L. (1993). Associations of serum lipid concentrations and obesity with mortality in women: 20 year follow up of participants in prospective population study in Gothenburg, Sweden. Br. Med. J. 307, 1385-1388.

Blumenfeld, H. (2002). Neuroanatomy Through Clinical Cases. Sunderland, MA: Sinauer Associates.

Bonaventure, A., Kurth, T., Pico, F., Barberger-Gateau, P., Ritchie, K., Stapf, C., and Tzourio, C. (2009). Triglycerides and risk of hemorrhagic stroke vs. ischemic vascular events: the three-city study. Atherosclerosis 210, 243-248.

Bowman, T. S., Sesso, H. D., Ma, J., Kurth, T., Kase, C. S., Stampfer, M. J., and Gaziano, J.M. (2003). Cholesterol and the risk of ischemic stroke. Am. Heart Assoc. 34, 2930-2934.

Chen, C. H., Eng, H. L., Chang, C. J., Tsai, T. T., Lai, M. L., Chen, H. Y., Liu, C. J., and Lin, T. M. (2003). 4G/5G promoter polymorphism of plasminogen activator inhibitor-1, lipid profiles, and ischemic stroke. J. Lab. Clin. Med. 142, 100-105.

Ebinger, M., Heuschmann, P. U., Jungehuelsing, G. J., Werner, C., Laufs, U., and Endres, M. (2010). The 'Berlin 'Cream\&Sugar'Study: the prognostic impact of an oral triglyceride tolerance test in patients after acute ischaemic stroke. Int. J. Stroke 5, 126-130.

Freiberg, J.J., Tybjaerg-Hansen, A., Jensen, J. S., and Nordestgaard, B. G. (2008). Nonfasting triglycerides and risk of ischemic stroke in the general population. JAMA 300, 2142-2152.

Gordon, T., Kannel, W. B., Castelli, W. P., and Dawber, T.R.(1981).Lipoproteins, cardiovascular disease, and death. The Framingham study. Arch. Intern. Med. 141, 1128-1131.

Haheim, L. L., Holme, I., Hjermann, I., and Leren, P. (1993). Risk factors of stroke incidence and mortality. A 12-year follow-up of the Oslo study. Stroke 24, 1484-1489.

Hasselblad, L., and Hedges, V. (1995). Meta-analysis of screening and diagnostic tests. Psychol. Bull. 117, 167-178.

studies examining the possible benefit of non-fasting triglyceride measurement, ideally differentiating between stroke subtypes, may be especially warranted.

\section{ACKNOWLEDGMENTS}

The research leading to these results has received funding from the Federal Ministry of Education and Research through the Grant Center for Stroke Research Berlin (01 EO 0801), the Volkswagen Foundation (Lichtenberg program to M. Endres), DFG (NeuroCure), and EU (European Stroke Network).

Havasi, V., Szolnoki, Z., Talián, G., Bene, J., Komlósi, K., Maász, A., Somogyvári, F., Kondacs, A., Szabó, M., and Fodor, L. (2006). Apolipoprotein A5 gene promoter region $\mathrm{T}-1131 \mathrm{C}$ polymorphism associates with elevated circulating triglyceride levels and confers susceptibility for development of ischemic stroke. J. Mol. Neurosci. 29, 177-183.

Hokanson, J. E., and Austin, M.A. (1996). Plasma triglyceride level is a risk factor for cardiovascular disease independent of high-density lipoprotein cholesterol level: a meta-analysis of population-based prospective studies. J. Cardiovasc. Risk 3, 213-219.

Iso, H., Sato, S., Kitamura, A., Imano, H., Kiyama, M., Yamagishi, K., Cui, R., Tanigawa, T., and Shimamoto, T. (2007). Metabolic syndrome and the risk of ischemic heart disease and stroke among Japanese men and women. Stroke 38, 1744-1751.

Jeppesen, J., Hein, H. O., Suadicani, P., and Gyntelberg, F. (1998). Triglyceride concentration and ischemic heart disease an eight-year follow-up in the Copenhagen male study. Am. Heart Assoc. 97, 1029-1036.

Labreuche, J., Touboul, P. J., and Amarenco, P. (2009). Plasma triglyceride levels and risk of stroke and carotid atherosclerosis: a systematic review of the epidemiological studies. Atherosclerosis 203, 331-345.

Laloux, P., Galanti, L., and Jamart, J. (2004). Lipids in ischemic stroke subtypes. Acta Neurol. Belg. 104, 13-19.

Lapidus, L., Bengtsson, C., Lindquist, O., Sigurdsson, J. A., and Rybo, E. (1985). Triglycerides-main lipid risk factor for cardiovascular disease in women? Acto Med. Scand. 217, 481-489.

Lindenstrom, E., Boysen, G., and Nyboe, J. (1994). Influence of total cholesterol, high density lipoprotein cholesterol, and triglycerides on risk of cerebrovascular disease: the Copenhagen City heart study. Br. Med. J. 309, 11-15.

Lipska, K., Sylaja, P. N., Sarma, P. S. Thankappan, K. R., Kutty, V. R. Vasan, R. S., and Radhakrishnan, K. (2007). Risk factors for acute ischae- mic stroke in young adults in South India. J. Neurol. Neurosurg. Psychiatry 78, 959-963.

Milionis, H. J., Liberopoulos, E., Goudevenos, J., Bairaktari, E. T., Seferiadis, K., and Elisaf, M. S. (2005). Risk factors for first-ever acute ischemic non-embolic stroke in elderly individuals. Int. J. Cardiol. 99, 269-275.

Mohanlal, N., and Holman, R. R. (2004).A standardized triglyceride and carbohydrate challenge. The oral triglyceride tolerance test A table elsewhere in this issue shows conventional and Systeme International (SI) units and conversion factors for many substances. Am. Diabetes Assoc. 27, 89-94.

Nakamura, T., Obata, J., Takano, H., Kawabata, K., Sano, K., Kobayashi, T., Fujioka, D., Saito, Y., Yano, T., and Kugiyama, K. (2009). High serum levels of remnant lipoproteins predict ischemic stroke in patients with metabolic syndrome and mild carotid atherosclerosis. Atherosclerosis 202, 234-240.

Njolstad, I.,Arnesen, E., and Lund-Larsen, P. G. (1996). Body height, cardiovascular risk factors, and risk of stroke in middle-aged men and women a 14-year follow-up of the Finnmark study. Circulation 94, 2877-2882.

Nordestgaard, B. G., Benn, M., Schnohr, P., and Tybjaerg-Hansen, A. (2007). Nonfasting triglycerides and risk of myocardial infarction, ischemic heart disease, and death in men and women. JAMA 298, 299-308.

Okamura, T., Kokubo, Y., Watanbe, M., Higashiyama, A., Ono, Y., Miyamoto, Y., Yoshimasa, Y., and Okayama, A. (2010). Triglycerides and non-highdensity lipoprotein cholesterol and the incidence of cardiovascular disease in an urban Japanese cohort: The Suita study. Atherosclerosis 209, 1.

Onat, A., Sarı, İ., Yazıcı, M., Can, G., Hergenç, G., and Avcı, G. Ş. (2006). Plasma triglycerides, an independent predictor of cardiovascular disease in men: a prospective study based on a population with prevalent metabolic syndrome. Int. J. Cardiol. 108, 89-95. 
Patel, A., Woodward, M., Campbell, D. J., Sullivan, D. R., Colman, S., Chalmers, J., Neal, B., and MacMahon, S. (2005). Plasma lipids predict myocardial infarction, but not stroke, in patients with established cerebrovascular disease. Eur. Soc. Cardiol. 26, 1910-1915.

Psaty, B. M., Anderson, M., Kronmal, R. A., Tracy, R. P., Orchard, T., Fried, L. P., Lumley, T., Robbins, J., Burke, G., Newman, A. B., and Furberg, C. D. (2004). The association between lipid levels and the risks of incident myocardial infarction, stroke, and total mortality: The Cardiovascular Health Study. J. Am. Geriatr. Soc. 52, 1639-1647.

Psaty, B. M., Furberg, C. D., Kuller, L. H., Cushman, M., Savage, P. J., Levine, D., O'Leary, D. H., Bryan, R. N., Anderson, M., and Lumley, T. (2001). Association between blood pressure level and the risk of myocardial infarction, stroke, and total mortality the cardiovascular health study. Am. Med. Assoc. 161, 1183-1192.

Rhoads, G. G., and Feinleib, M. (1983). Serum triglyceride and risk of coronary heart disease, stroke, and total mortality in Japanese-American men. Arterioscler. Thromb. Vasc. Biol. 3,316-322.

Ridker, P. M. (2008). Fasting versus nonfasting triglycerides and the prediction of cardiovascular risk: do we need to revisit the oral triglyceride tolerance test? Clin. Chem. 54, 11-13.

Ryu, J.E., Howard, G., Craven, T.E., Bond, M. G., Hagaman, A. P., and Crouse, J. R. (1992). Postprandial triglyceridemia and carotid atherosclerosis in middle-aged subjects. Stroke 23, 823-828.

Sacco, R. L., Benson, R. T., Kargman, D. E., Boden-Albala, B., Tuck, C., Lin, I. F., Cheng, J. F., Paik, M. C., Shea, S., and Berglund, L. (2001). High-density lipoprotein cholesterol and ischemic stroke in the elderly The Northern
Manhattan Stroke Study. Am. Med. Assoc. 285, 2729-2735.

Saidi, S., Slamia, L. B., Ammou, S. B., Mahjoub, T., and Almawi, W.Y. (2007). Association of apolipoprotein E gene polymorphism with ischemic stroke involving large-vessel disease and its relation to serum lipid levels. J. Stroke Cerebrovasc. Dis. 16, 160-166.

Salonen, J.T., Puska, P., Tuomilehto, J., and Homan, K. (1982). Relation of blood pressure, serum lipids, and smoking to the risk of cerebral stroke. A longitudinal study in Eastern Finland. Stroke $13,327-333$.

Sarti, C., and Gallagher, J. (2006). The metabolic syndrome prevalence, CHD risk, and treatment. J. Diabetes Complicat. 20, 121-132.

Sarwar, N., Danesh, J., Eiriksdottir, G., Sigurdsson, G., Wareham, N., Bingham, S., Boekholdt, S. M., Khaw, K. T., and Gudnason, V. (2006). Triglycerides and the risk of coronary heart disease. 10158 incident cases among 262525 participants in 29 western prospective studies. Circulation 115, 450-458.

Shahar, E., Chambless, L. E., Rosamond, W. D., Boland, L. L., Ballantyne, C. M., McGovern, P. G., and Sharrett, A. R. (2003). Plasma lipid profile and incident ischemic stroke the atherosclerosis risk in communities (ARIC) study. Am. Heart Assoc. 34, 623.

Shearman, A. M., Cooper, J. A., Kotwinski, P.J., Humphries, S. E., Mendelsohn, M. E., Housman, D. E., and Miller, G. J. (2005). Estrogen receptor a gene variation and the risk of stroke. Am. Heart Assoc. 112, 2138-2142.

Shimo-Nakanishi, Y., Urabe, T., Hattori, N., Watanabe, Y., Nagao, T., Yokochi, M., Hamamoto, M., and Mizuno, Y. (2001). Polymorphism of the lipoprotein lipase gene and risk of atherothrombotic cerebral infarction in the Japanese. Am. Heart Assoc. 32, 1481-1486.
Simons, L. A., McCallum, J., Friedlander, Y., and Simons, J. (1998). Risk factors for ischemic stroke Dubbo study of the elderly. Am. Heart Assoc. 29, 1341-1346.

Simons, L. A., Simons, J., Friedlander, Y., and McCallum, J. (2001). Cholestero and other lipids predict coronary heart disease and ischaemic stroke in the elderly, but only in those below 70 years. Atherosclerosis 159, 201-208.

Stensvold,I., Tverdal, A., Urdal,P., and GraffIversen, S. (1993). Non-fasting serum triglyceride concentration and mortality from coronary heart disease and any cause in middle aged Norwegian women. Br. Med. J. 307, 1318-1322.

Stroup, D. F., Berlin, J. A., Morton, S. C., Olkin, I., Williamson, G. D., Rennie, D., Moher, D., Becker, B. J., Sipe, T. A., and Thacker, S. B. (2000). Metaanalysis of observational studies in epidemiology a proposal for reporting. Am. Med. Assoc. 283, 2008-2012.

Tanne, D., Koren-Morag, N., Graff, E. and Goldbourt, U. (2001). Blood lipids and first-ever ischemic stroke/ transient ischemic attack in the bezafibrate infarction prevention (BIP) registry high triglycerides constitute an independent risk factor. Am. Heart Assoc. 104, 2892-2897.

Tell, G. S., Crouse, J. R., and Furberg, C. D. (1988). Relation between blood lipids, lipoproteins, and cerebrovascular atherosclerosis. A review. Stroke 19, 423-430.

Tokuda, Y., and Stein, G. H. (2005) Serum lipids as protective factors for subarachnoid hemorrhage. J. Clin. Neurosci. 12, 538-541.

Towfighi, A., and Ovbiagele, B. (2008). Metabolic syndrome and stroke. Curr. Diab. Rep. 8, 37-41.

Wannamethee, S. G., Shaper, A. G., and Ebrahim, S. (2000). HDL-cholesterol, total cholesterol, and the risk of stroke in middle-aged British men. Am. Heart Assoc. 31, 1882.
Whitehead, A. (2002). Meta-Analysis of Controlled Clinical Trials. Chichester: Wiley.

Woo, J., Lau, E., Lam, C. W., Kay, R., Teoh, R., Wong, H. Y., Prall, W. Y., Kreel, L., and Nicholls, M. G. (1991). Hypertension, lipoprotein (a), and apolipoprotein AI as risk factors for stroke in the Chinese. Stroke 22, 203-208.

Zilversmit, D. B. (1979). Atherogenesis: a postprandial phenomenon. Circulation 60, 473-485.

Zimmermann,R.Strauss,J.G.,Haemmerle, G.,Schoiswohl,G., Birner-Gruenberger, R., Riederer, M., Lass, A., Neuberger, G., Eisenhaber, F., Hermetter, A., and Zechner, R. (2004). Fat mobilization in adipose tissue is promoted by adipose triglyceride lipase. Am. Assoc. Adv. Sci. 306, 1383-1386.

Conflict of Interest Statement: The authors declare that the research was conducted in the absence of any commercial or financial relationships that could be construed as a potential conflict of interest.

Received: 04 June 2010; accepted: 15 September 2010; published online: 25 October 2010

Citation: Leonards C, Ebinger M, Batluk J, Malzahn U, Heuschmann P and Endres $M$ (2010) The role of fasting versus non-fasting triglycerides in ischemic stroke: a systematic review. Front. Neur. 1:133. doi: 10.3389/ fneur.2010.00133

This article was submitted to Frontiers in Stroke, a specialty of Frontiers in Neurology.

Copyright () 2010 Leonards, Ebinger, Batluk, Malzahn, Heuschmann and Endres. This is an open-access article subject to an exclusive license agreement between the authors and the Frontiers Research Foundation, which permits unrestricted use, distribution, and reproduction in any medium, provided the original authors and source are credited. 